\section{'Indulgence' and 'Dazzle': Two New White Wine Grapes for the U.S. Mid-South}

\author{
Renee T. Threlfall \\ Department of Food Science, University of Arkansas System Division of \\ Agriculture, 2650 North Young Avenue, Fayetteville, AR 72704
}

John R. Clark and James N. Moore
Department of Horticulture, University of Arkansas System Division of
Agriculture, 316 Plant Science, Fayetteville, AR 72701

Justin R. Morris

Department of Food Science, University of Arkansas System Division of Agriculture, 2650 North Young Avenue, Fayetteville, AR 72704

Additional index words. cultivar, enology, fruit breeding, fruit quality, Vitis

\begin{abstract}
'Indulgence' and 'Dazzle' wine grapes are new cultivars (Vitis hybrid) developed by the University of Arkansas System Division of Agriculture (UA System). These grapes are the third and fourth wine grape cultivars from the program. These white wine grape cultivars have shown good adaptation and consistent productivity in Arkansas. Enological evaluations have shown that these cultivars produced high-quality wines from fruit grown in Arkansas. It is envisioned that these cultivars will be best used by Arkansas wine grape growers as well as those in the midSouth. Winemakers can use these cultivars to expand unique wine options for the state and region.
\end{abstract}

\section{Origin}

'Indulgence' is a result of a cross of 'Seyval' × 'Muscat Ottonel' made in 1989 by James N. Moore. 'Seyval' (a French-American hybrid, also known as 'Seyve-Villard 5276') originated in France from $V$. vinifera hybridized with the American species $V$. lincecumii and $V$. rupestris, and was released in

Received for publication 13 Sept. 2021. Accepted for publication 17 Dec. 2021.

Published online 4 February 2022.

Special thanks to David Gilmore, Effie Gilmore, Kay Buck, John Ridgeway, Dan Chapman, Jackie Lee, James McClellan, Sandra Sleezer, Kenda Woodburn, Gary Main, Sarah Mayfield, Taunya Ernst, and Erika Henderson for assistance in data collection in the evaluation of 'Indulgence' and 'Dazzle' wine grapes in Arkansas.

R.T.T. is a Research Scientist.

J.R.C. is a Distinguished Professor.

J.N.M. and J.R.M. are Distinguished Professor Emeritus, deceased.

R.T.T. is the corresponding author. E-mail: rthrelf@uark.edu.

This is an open access article distributed under the CC BY-NC-ND license (https://creativecommons. org/licenses/by-nc-nd/4.0/). the 1920s. 'Seyval' is a white wine grape that is well adapted in the eastern United States because of its winterhardiness that allows production in the upper South, Midwest, and Northeast. 'Seyval' wine is generally considered neutral to slight fruity. 'Muscat Ottonel' is a $V$. vinifera cultivar that originated in France in the $1850 \mathrm{~s}$, has demonstrated more cold hardiness than other muscat-flavored $V$. vinifera cultivars in Europe, and is commonly grown in the Alsace region of France. This grape and resulting wine has a very distinct muscat flavor, with notes of grapefruit, floral, and green apple, that presents in the progeny. The original plant of 'Indulgence' was selected in 1992 by Moore and tested as selection Ark. 2359. Viticultural evaluation of 'Indulgence' was conducted through 2021.

'Dazzle' resulted from a cross of 'Gewürztraminer' × 'Melody' made in 1992 by James N. Moore. The female parent 'Gewürztraminer' is an $V$. vinifera cultivar of European origin with pink fruit that produces an aromatic wine. 'Melody' was released from the New York State Agricultural Experiment Station in 1996 and produces white wine of neutral fruitiness with floral overtones. 'Melody' has in its background $V$. vinifera hybridized with the American species V. labrusca L., V. lincecumii Buckley, and $V$. rupestris Scheele. 'Dazzle' was selected in 1995 by Moore and John R. Clark and tested as Ark. 2574. Viticultural evaluation of 'Dazzle' was conducted through 2021.

All original vines of these cultivars were selected from a seedling vineyard located at the UA System Fruit Research Station (FRS), Clarksville, AR (west-central Arkansas; lat. $35^{\circ} 28^{\prime} 17^{\prime \prime} \mathrm{N}$, long. $93^{\circ} 80^{\prime} 0^{\prime \prime}$; USDA hardiness zone 7a). After selection, a single, ownrooted, three-vine plot of each cultivar was established at FRS on a fine sandy loam soil the year after selection and began fruiting in the third year after planting. Vines of previously released Arkansas cultivars, Enchantment and Opportunity, were also present in this vineyard (Clark et al., 2018). Additional vines of all cultivars were planted in 2014 to have more fruit for wine production and evaluation. 'Vignoles', a common white wine hybrid grape cultivar, was planted at FRS in 2016 as a wine comparison only (2019-21; no viticultural ratings or data were collected for this cultivar). All vines were trained to a bilateral, high-cordon/curtain training system and pruned to three- to fourbud spurs annually. Vines were spaced $2.4 \mathrm{~m}$ apart and rows, $3.1 \mathrm{~m}$.

Observations were made for a range of characteristics most years on 'Indulgence' from 1995 through 2021 and on 'Dazzle' for 1998 through 2021. Subjective ratings were done in some years for cluster fill, vigor, and health on these plots using a scale of 1 to 10 points, with 1 point being very poor for the character rated to 10 points for exceptional or usually most desired. A character rating where 10 points is not desired is cluster fill, where a 10-point rating represents a very tight cluster that could exacerbate disease development. A cluster rating of 7 to 8 points is preferred. In addition, a rating for vigor of 9 or 10 points reflected excessive vegetative vigor; a rating of 7 to 8 points is again more desirable. Objective data were collected for yield, berry weight (average of 25 berries per cultivar), and cluster weight (average of five clusters) for 2017-20 (Table 1). Berry samples were taken before harvest, and harvest date was determined based on fruit composition of $\mathrm{pH} 3.4$ to 3.6 , titratable acidity of $0.6 \%$ to $0.75 \%$, and soluble solids of $18 \%$ to $20 \%$. Means and SD over years were calculated for each variable and cultivar.

Overall, winter temperatures ranged from the low temperatures of $-26^{\circ} \mathrm{C}$ in 2021 and $-17^{\circ} \mathrm{C}$ (winters of 1996, 1997, 2011, and 2018) to higher midwinter lows of -8 to $-9{ }^{\circ} \mathrm{C}$ (winters of 2008 and 2013) during the evaluation of these cultivars. Vines survived these winter lows with minimal to no winter damage to unpruned canes as well as cordons.

Fungicides were applied similar to a commercial requirement to control black rot (Guignardia bidwellii Viala \& Ravaz), powdery mildew [Erysiphe necator Schw.; syns. Uncinula necator (Schw.) Burr., E. tuckeri Berk., $U$. americana Howe, and U. spiralis Berk. \& Curt; anamorph Oidium tuckeri Berk.], downy mildew (Plasmopara viticola Berl. \& de Toni), and anthracnose (Elsinoë ampelina Shear) in seedling and selection plantings. However, the last application of any fungicide in the three-vine plots was usually done near the end of June to early July, 7 to 8 weeks before harvest through 2015. This extended period from the last spray until harvest resulted from the vines being grown in a vineyard with earlier ripening grape breeding selections and cultivars, and preharvest intervals prevented continued spray applications after late June to early July. This resulted in increased disease pressure on the wine grape cultivars in these years resulting from the long interval from last spray application until harvest. Fungicide sprays on the vines were continued until late 
Table 1. Average harvest date, total yield per vine, cluster weight, and berry weight for 'Dazzle', 'Indulgence', 'Enchantment', and 'Opportunity' wine grapes, University of Arkansas System Division of Agriculture Fruit Research Station, Clarksville, AR.

\begin{tabular}{|c|c|c|c|c|c|c|}
\hline Cultivar & Type of grape/wine & Harvest date $\mathrm{z}^{\mathrm{z}}$ & Total yield per vine $(\mathrm{kg})^{\mathrm{z}}$ & Total yield per vine $(\mathrm{lb})^{\mathrm{z}}$ & Cluster wt $(\mathrm{g})^{\mathrm{z}}$ & Berry wt (g) \\
\hline Dazzle & White & August 15 (7.5) & $9.8(5.8)$ & $21.6(12.7)$ & $162.3(69.3)$ & $1.9(0.2)^{\mathrm{y}}$ \\
\hline Indulgence & White & August 14 (5.6) & $16.6(10.7)$ & 36.7 (23.4) & $153.1(67.3)$ & $2.5(0.1)^{\mathrm{x}}$ \\
\hline Enchantment & Red & August 19 (8.7) & $12.0(3.0)$ & $26.5(6.5)$ & $129.4(42.2)$ & $1.6(0.2)^{\mathrm{x}}$ \\
\hline
\end{tabular}

${ }^{\mathrm{z}}$ Mean (SD) calculated for years $2017-20$.

${ }^{\mathrm{y}}$ Mean (SD) calculated for years 2017 and 2020 only.

${ }^{\mathrm{x}}$ Mean (SD) calculated for years 2017 and 2019-20.

July to early August in 2016-21 to extend disease control in these years.

Insecticides were applied as needed to control climbing cutworm (several species are common, including Agrotis ipsilon Hufnagel, Feltia jaculifera Guenée, and Peridroma saucia Hübner) and grape berry moth (Paralobesia viteana Clemens). No control near harvest was conducted for spotted-wing drosophila (Drosophila suzukii Matsumura), and no damage from this insect was observed. Weeds were controlled by applications of preemergence and postemergence herbicides applied annually. All vines received trickle irrigation as required. Vines were fertilized annually in March or April with nitrogen or complete fertilizers. No shoot or leaf removal practices were conducted on the vines.

\section{Grape, Juice, and Wine Composition and Quality}

Grape, juice, and wine quality and composition were evaluated from 1997 to 2021 for 'Indulgence' and from 2000 to 2021 for 'Dazzle' (data only shown for 2017-21). Wine of 'Indulgence' was made in 1997-2000, 2002, and 2015-21. Wine of 'Dazzle' was made in 2000-03, 2015, and 2017-21. No data for the 2021 wines are available because the wines are still in production. Grape and wine composition and quality were compared with other Vitis white wine cultivars Opportunity and Vignoles grown at the UA System FRS (Table 2). Grapes of all cultivars were hand-harvested from the UA System FRS, Clarksville, AR, and delivered to the UA System Food Science Department, Fayetteville, AR, for wine production using a protocol for microvinification, depending on quantity available and quality of the grapes. The amount of fruit processed ranged from 14 to $73 \mathrm{~kg}$ /cultivar.

After harvest, the grapes were stored overnight or over the weekend at $2{ }^{\circ} \mathrm{C}$, removed from cold storage, crushed and destemmed, and the must (juice, pulp, seeds, and skins) was placed in a food-grade container. Sulfur dioxide (as potassium metabisulfite) was added at crush at a rate of $30 \mathrm{mg} / \mathrm{L}$. All grapes were processed in a traditional white wine style, so the must was pressed, and the juice was fermented. The must was pressed in a $30-$ or $70-\mathrm{L}$ stainless steel bladder press (Enoagricola Rossi Hydropress, Calzolaro, Italy) using three 10-min press cycles and a pressure of $207 \mathrm{kPa}$. The juice was collected in glass carboys. The juice was cold-settled at $2{ }^{\circ} \mathrm{C}$, racked, and adjusted before fermentation.
The acids and sugar levels of the juice were adjusted to have a $\mathrm{pH}$ of 3.2 to 3.6 , a titratable acidity of $0.60 \%$ to $0.75 \%$, and soluble solids of $20 \%$ to $21 \%$. Wines were inoculated with commercial active dried yeast and yeast nutrients (Lallemand, Inc., Montreal, Canada) and were fermented at 15 to $21^{\circ} \mathrm{C}$. The yeast type and nutrients used in wine production varied by year. The fermented wine was racked several times during fermentation to remove spent yeast cells and prevent the production of off flavors. After completion of fermentation $(<0.5 \%$ residual sugar), sulfur dioxide was added as potassium metabisulfite to prevent oxidation and spoilage. Rates of sulfur dioxide addition were based on the $\mathrm{pH}$ of the wine. Wines were cold-stabilized. Wines were bottled in $375-$ or $750-\mathrm{mL}$ glass bottles with screw caps or corks and stored at $15^{\circ} \mathrm{C}$.

Juice samples from grape berries were measured with various digital refractometers to determine soluble solids (expressed as a percentage). Titratable acidity (expressed as grams per $100 \mathrm{~mL}$ or percentage of tartaric acid) and $\mathrm{pH}$ of juice and wine were measured. Six grams or $5 \mathrm{~mL}$ of the sample was added to $50 \mathrm{~mL}$ degassed, deionized water and titrated with $0.1 \mathrm{~N}$ sodium hydroxide to an endpoint of $\mathrm{pH}$ 8.2. Wine was degassed before analysis. Ethanol levels (expressed as percent volume/volume) of the wines were measured by ebulliometer or high-performance liquid chromatography. Because the evaluations were conducted over 23 years, the equipment used for the juice and wine analysis varied. A grape and wine industrybased expert panel was used for sensory evaluation of 'Indulgence' and 'Dazzle' wine in 2017.

\section{Industry Sensory Panel}

The industry sensory panel was conducted at the UA System Department of Food Science in 2017 (Institutional Review Board no. 05-11193). 'Dazzle', 'Indulgence', and 'Opportunity' produced in 2015 and 2017 were evaluated. The 2015 wines were evaluated at 2 years of storage at $15^{\circ} \mathrm{C}$, and the 2017 wines were evaluated at 0 month of storage at $15^{\circ} \mathrm{C}$. In total, 26 panelists from the wine industry evaluated wines for liking of wine appearance, aroma, flavor, sweetness, acidity, and overall impression, and provided comments on wine appearance, aroma, flavor, and overall impression. Each panelist evaluated $\approx 30 \mathrm{~mL}$ of wine, and each wine was evaluated one time. The wines were served monadically (one at a time) at $15^{\circ} \mathrm{C}$ in wine glasses, and all panelists evaluated wines in the same order. Panelists were instructed to cleanse their palate with water between samples. Expectorant cups were provided. The panelists used a 9-point hedonic scale $(1$ point $=$ dislike extremely, 9 points $=$ like extremely) to indicate their liking of wine appearance, aroma, flavor, sweetness, acidity, and overall impression. After evaluating each attribute, panelists were instructed to provide comments about wine appearance, aroma (smell), flavor (taste), and overall impression.

\section{Description and Performance of Fruit and Vines}

Fruit characteristics: 'Indulgence'. The average harvest date for 'Indulgence' was 14 Aug. (Table 1). Harvest date varied between 8 and 21 of August from 2017 to 2021. Yield of 'Indulgence' averaged $16.6 \mathrm{~kg} / \mathrm{vine}$, considered a good commercial yield for a white wine grape in Arkansas, and was similar to 'Opportunity'. Cluster weight averaged $153.1 \mathrm{~g}$. The cluster fill rating averaged 6.5, indicating a loose cluster (data not shown) (Fig. 1). There was substantial variation in cluster density among years. Figure 1 shows the full, compact cluster potential of 'Indulgence'. The cluster density reflects some variation in fruit set for 'Indulgence', with ratings for years 2001, 2005, and 2006 being the lowest for cluster fill. During these years, 4 to $9 \mathrm{~d}$ of rain occurred during the first 2 weeks of May, when bloom normally occurs for 'Indulgence', and rainfall could have contributed to the reduced berry set, resulting in less-full clusters. Average berry weight was $2.5 \mathrm{~g}$. Fruit cracking was not observed for 'Indulgence' following the summer rains near harvest. Juice after pressing had a soluble solids content of $16.9 \%$, a $\mathrm{pH}$ of 3.29 , and titratable acidity of $0.64 \mathrm{~g} / 100 \mathrm{~mL}$ (Table 2). The flavor of 'Indulgence' grapes at harvest is a very strong muscat flavor consistent in all years.

Vine characteristics: 'Indulgence'. Vines of 'Indulgence' have an upright growth habit. Vine vigor was moderate, with a rating of 6.7, the same rating as 'Enchantment' and lower in vigor than 'Opportunity', with a rating of 7.6 (data not shown). Health of the vines was consistently rated good, averaging 7.4 (data not shown). Some magnesium chlorosis symptoms were observed in some years, but did not appear to affect vine performance. Observations for diseases on 'Indulgence' indicated powdery mildew on leaves in 4 of 27 years and on fruit in 1 year. Downy 
Table 2. Composition of juice at press and wine at bottling for 'Dazzle', 'Indulgence', 'Opportunity', and 'Vignoles' from the University of Arkansas System Division of Agriculture Fruit Research Station, Clarksville, AR (2017-21).

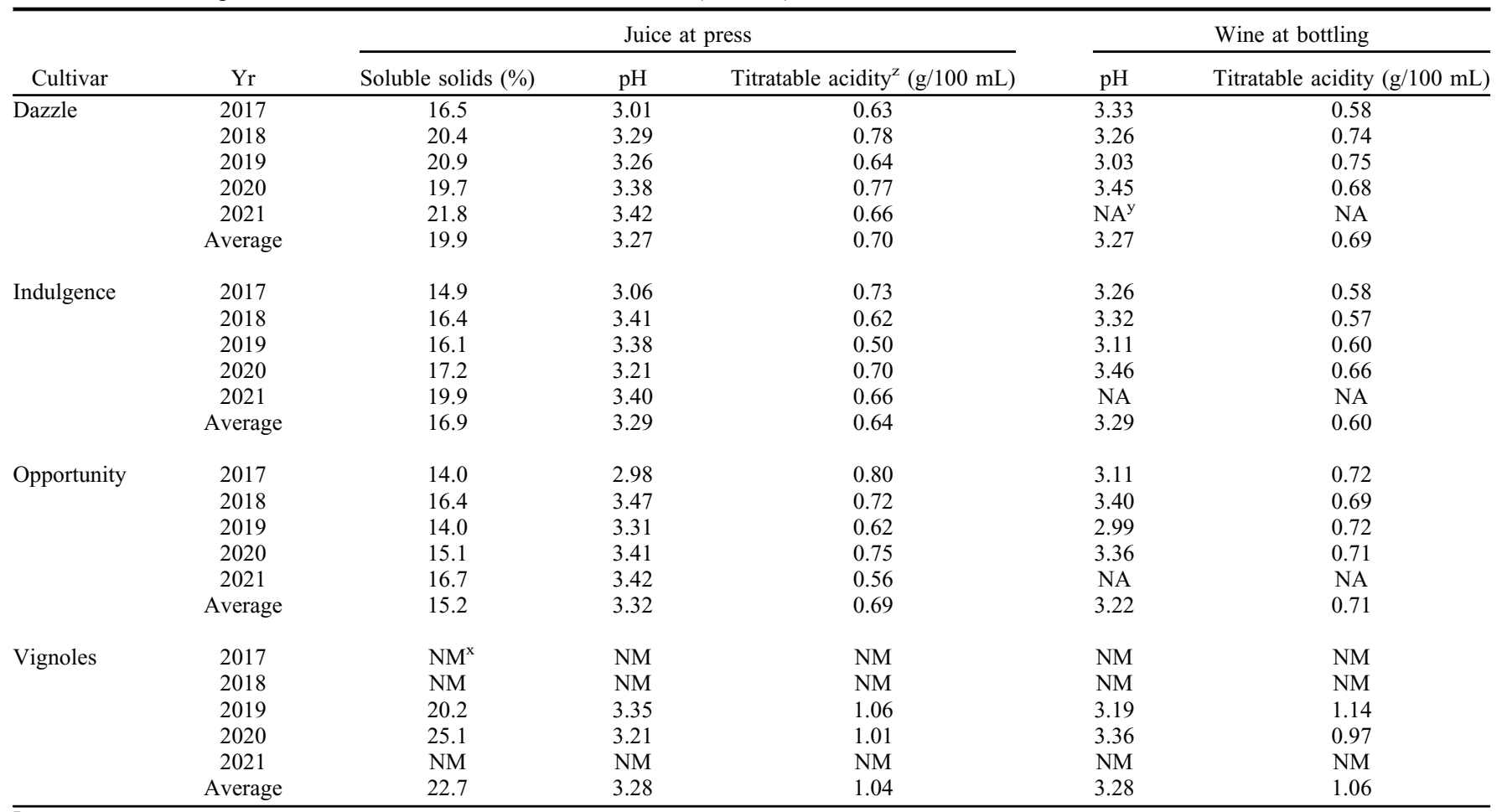

${ }^{\mathrm{z}}$ Measured as tartaric acid.

${ }^{\mathrm{y}}$ Data not available for 2021 wines because wine production has not ended.

${ }^{\mathrm{x}}$ Wine was not made during these years.

mildew was not observed, even in heavy downy mildew infection years such as 2002 , 2004, and 2013. Neither anthracnose nor black rot was observed in any years, but these earlier season diseases were likely controlled by early- to midseason fungicide applications, and no resistance is implied for them. Phomopsis cane and leaf spot [Phomopsis viticola (Sacc.) Sacc.] was thought to cause substantial

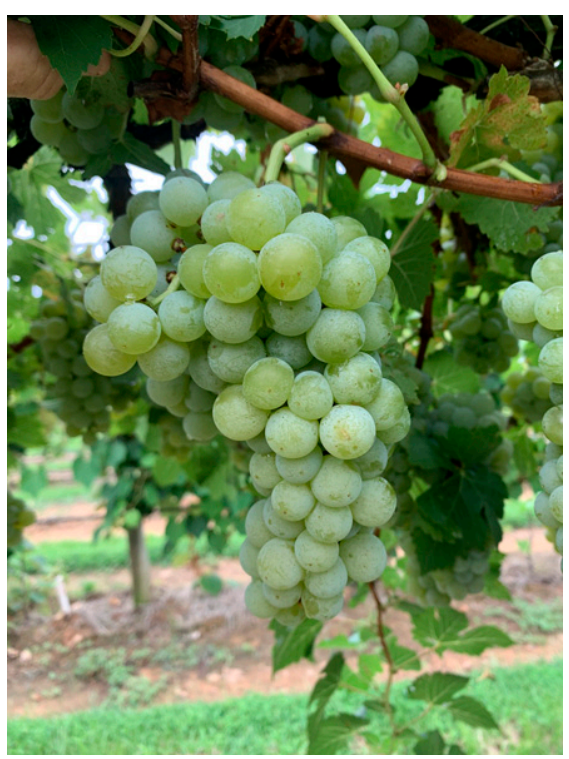

Fig. 1. Cluster of 'Indulgence' white wine grape grown at the University of Arkansas System Division of Agriculture Fruit Research Station (Clarksville, AR, 2020). damage to pedicels and rachises in 2017 and 2019, but pathogen identification was not conducted. Careful control of rot near harvest will be needed to ensure disease-free fruit of 'Indulgence'. It is hoped that the minimal observation of common diseases reflects the potential to manage disease pressures with average or possibly slightly reduced applications of fungicides.

The adaptation of 'Indulgence' to the climate at FRS was very good and reflective of its potential for reliable production in Arkansas and the mid-South region. Winter injury was not observed during 'Indulgence' testing, even with winter lows of $-26^{\circ} \mathrm{C}$ in 2021 and $-17^{\circ} \mathrm{C}$ experienced in four additional winters, reflecting good hardiness for this location. Heat damage was not noted, even with excessively hot summers such as that of 2012 , with average high temperatures of 36 and $34^{\circ} \mathrm{C}$ in July and August, respectively $\left(4^{\circ} \mathrm{C}\right.$ higher than typical).

Fruit characteristics: 'Dazzle'. The average harvest date for 'Dazzle' was 15 Aug., and this date varied between 7 and 25 of August from 2017 to 2021 (Table 1). It was noted that 'Dazzle' has the potential for a later harvest. Yield of 'Dazzle' averaged $9.8 \mathrm{~kg} / \mathrm{vine}$, which is lower than comparison cultivars. However, crop load was very consistent over the many years of observing the vines. Cluster weight averaged $162.3 \mathrm{~g}$. The cluster fill rating averaged 9.0, indicating a compact cluster but not as tight as 'Opportunity' (data not shown) (Fig. 2). The cluster fill was very consistent, with the exception of 2006 , when clusters were rated much less full, but this was likely a result of rainfall during bloom. Clusters often exhibit a limited number of "shot" or green, small berries present at harvest. Berries averaged 1.9 g. Fruit cracking was not observed for 'Dazzle' following summer rains near harvest. In the juice at pressing, the soluble solids averaged $19.9 \%, \mathrm{pH}$ averaged 3.27, and titratable acidity averaged $0.70 \mathrm{~g} / 100 \mathrm{~mL}$ (Table 2). The flavor of 'Dazzle' grapes at harvest is light and semifruity, which is reflective of its 'Gewürztraminer' parent, and was consistent in all years.

Vine characteristics: 'Dazzle'. Vines of 'Dazzle' have a growth habit that is more procumbent than 'Indulgence', similar to that of 'Opportunity'. Vine vigor is moderate to semivigorous, with a rating of 7.8 , near that of 'Opportunity' (rating, 7.6) and greater than that of 'Enchantment' and 'Indulgence' (rating, 6.7) (data not shown). Health of the vines was rated good consistently, averaging 8.3, the highest among the comparison cultivars (rating range, 7.0-7.8; data not shown). Observations for diseases on 'Dazzle' indicated powdery mildew was seen on leaves in 2 of 23 years and on fruit 1 year. Downy mildew was not observed, even in heavy downy mildew infection years such as 2002, 2004, and 2013. Neither anthracnose nor black rot was observed in any year, but these earlier season diseases were likely controlled by early- to midseason fungicide applications, and no resistance is implied for them. Phomopsis cane and leaf spot was thought to cause damage to pedicels and rachises in 2016, when substantial crop loss was seen as a result of rachis and pedicel necrosis, but 


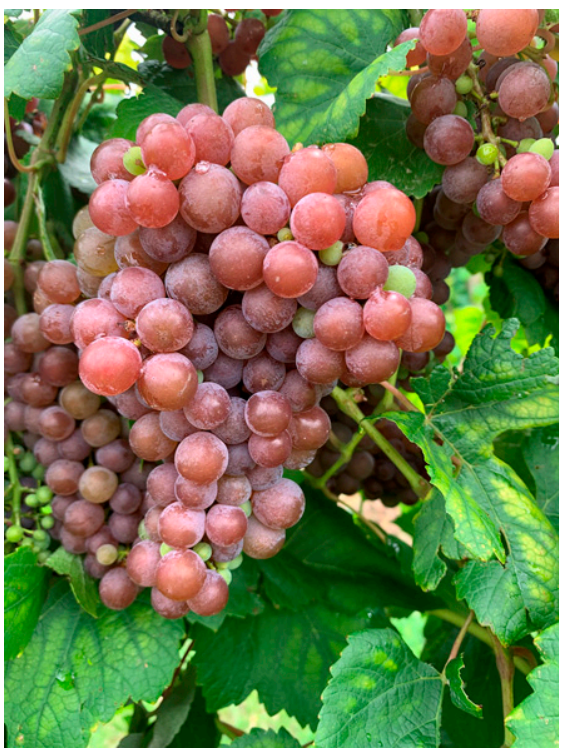

Fig. 2. Cluster of 'Dazzle' white wine grape grown at the University of Arkansas System Division of Agriculture Fruit Research Station (Clarksville, AR, 2020).

pathogen identification was not conducted. Careful control of rot near harvest will be needed to ensure disease-free fruit of 'Dazzle'. It is hoped that the minimal observation of common diseases reflects the potential to manage disease pressures with average or possibly slightly reduced applications of fungicides.

The adaptation of 'Dazzle' to the climate at FRS was very good and reflective of its potential for reliable production. Winter injury was not observed during its testing, even with winter lows of $-26^{\circ} \mathrm{C}$ in 2021 and $-17^{\circ} \mathrm{C}$ experienced in four additional winters, reflecting good hardiness for this location. Heat damage was not noted, even with some excessively hot summers, such as that of 2012

\section{Description of Grape, Juice, and Wine Composition and Quality}

Observations of harvested fruit for wine production. After harvest, the grapes were transported to the UA System Food Science Department for wine production. The grapes were examined visually for quality attributes and tasted for flavor attributes before wine production. There were not many quality issues with the fruit in the years the wines were evaluated. It was noted that 'Indulgence' had a muscat-like flavor with notes of grapefruit, floral, green apple; the skins were not astringent; and the pulp in the grape was prominent. It was noted that 'Dazzle' had pink skin with floral, grapefruit, apple, and citrus flavors, and the grape skin was neutral. Data on juice composition at press and wine composition at bottling for these selections from 2017 to 2021 are reported in Table 2.

Wine composition and quality. Juice yield at crush from 2017 to 2021 was about $3.8 \mathrm{~L} \mathrm{(1}$ gal) of juice for $6 \mathrm{~kg}(13 \mathrm{lb})$ of 'Indulgence' and for $6.5 \mathrm{~kg}(14 \mathrm{lb})$ for 'Dazzle'. For wine production, 'Indulgence' needed sugar additions most years and acid additions some years, whereas sugar and acid additions for 'Dazzle' were not needed as much. It was noted that 'Indulgence' is pulpy, so it does not settle well during cold settling. However, the addition of pectinase to the juice after pressing, and the use of bentonite, helped cold settling. To maintain the muscat-like aroma of 'Indulgence' and the 'Gewürztraminer'-like aromas and flavors, it is recommended to ferment these cultivars at a lower temperature $\left(15^{\circ} \mathrm{C}\right)$. From 2017 to 2020 , the average wine $\mathrm{pH}$ of 'Dazzle' and 'Indulgence' was 3.27 and 3.29, respectively, and the titratable acidity was $0.69 \mathrm{~g} / 100 \mathrm{~mL}$ and $0.60 \mathrm{~g} / 100 \mathrm{~mL}$, respectively. The ethanol levels of the wines were $10 \%$ to $12 \%$ (data not shown). Data for 'Opportunity' and 'Vignoles' wines are included in Table 2 as a comparison of white wine cultivars grown in Arkansas. 'Opportunity' wines (2017-20) had a pH of 3.22 and a titratable acidity of $0.71 \mathrm{~g} / 100 \mathrm{~mL}$. 'Vignoles' wines (2019-20) had a pH of 3.28 and a titratable acidity of $1.06 \mathrm{~g} / 100 \mathrm{~mL}$, with residual sugar levels less than $0.5 \%$.

Industry sensory panel. The industry sensory panel evaluated 'Dazzle', 'Indulgence', and 'Opportunity' wines produced in 2015 and 2017. 'Opportunity' was presented to compare the new cultivars to a previously released white wine cultivar. These wines were not finished commercially (no residual or added sugar in the wines). The 2015 wines were evaluated at 2 years of storage at $15^{\circ} \mathrm{C}$, and the 2017 wines were evaluated at 0 month of storage at $15^{\circ} \mathrm{C}$. The data on sensory wine attributes for liking using the 9point hedonic scale were discussed but not shown in this article. There were more aroma and flavor descriptors in 2017 wines compared with 2015 wines for each of the attributes of the different wines (Table 3). Commercial white wines are typically consumed within 2 years of production, so the more prominent aromas and flavors of the younger wine were expected.

On average, the appearance, aroma, flavor, and overall impression of the wines were scored "like moderately"; the sweetness and acidity of the wines were scored "like slightly" (data not shown), indicating an overall positive reaction to 'Dazzle', 'Indulgence', and 'Opportunity' wine sensory attributes. The appearance of 'Dazzle' wines was described as golden and clear. The appearance of 'Indulgence' wines was described as clean, clear, bright, golden, light, and slightly green.

'Indulgence' wines from 2017 had greater aroma liking scores than the other wines. The 2017 'Indulgence' wine aroma was scored "like very much," the aroma of 2015 'Dazzle' wine was scored "like slightly," and the aroma of all other wines was scored "like moderately." It is possible that the greater aroma liking ratings for 2017 'Indulgence' wine were a result of the greater amounts of floral, herbal, and spicy aroma compounds. In general, the 2017 wines were described as fruitier, more floral, and overall more pleasing than the 2015 wines. The fruity and floral aromas of white wines can dissipate during storage, explaining the difference in aroma descriptors between the 2015 and 2017 wines. The aroma of 2015 'Indulgence' wine was described as faint, citrus, 'Riesling'-like, and light, indicating the characteristic muscat character of 'Indulgence' grapes/wine was not as present in the 2015 wine. The aroma of 2017 'Indulgence' wine was described as floral, beautiful, citrus, good nose, peach, muscat-like, and honeysuckle. These aroma descriptors were closer to the characteristic floral, fruity, herbal, and spicy aromas of muscat wines. The aroma of 2015 'Dazzle' wine was described as soft, pleasant, spicy, and faint, and the aroma of 2017 'Dazzle' wine was described as fruity, green apple, bell pepper, soft, and hay/straw. These descriptors are consistent with the apple, pear, apricot, grapefruit, spice, rose, and floral aromas found in hybrids with 'Gewürztraminer' parentage.

Similar to the aroma ratings, the flavor of 2017 'Indulgence' wine was rated the highest ("like moderately"), and the flavor of 2015 'Dazzle' wine was rated the lowest ("like slightly"). The flavor of 2015 'Indulgence' wine was described as refreshing, grapefruit, pleasant, and gentle, and the flavor of 2017 'Indulgence' wine was described as pleasant, confident, fruity, peach, stone fruit, clean, and good mouthfeel. The flavor of 2015 'Dazzle' wine was described as very pleasant, citrus, fruit, and clean; the flavor of 2017 'Dazzle' wine was described as stone fruit, peach, clean, crisp, good finish, and nice tannins. These results suggest that the flavor of the 2017 wines was preferable to the 2015 wines.

There were no obvious differences among the wines for sweetness and acidity liking. Wines were scored "like slightly" to "like moderately" for these attributes. The 'Indulgence' wines from 2015 and 2017 had slightly greater sweetness and acidity liking ratings than other wines. This could have been a result of the greater amounts of fruity/floral aroma compounds in these wines that masked the acidity. In general, wines were fairly acidic and very dry (low residual sugars). To reduce the perceived acidity of wines, winemakers could finish wines commercially by adding small amounts of sugar before bottling to balance sourness and mouthfeel.

The overall impression liking of 2017 'Indulgence' wine was scored "like very much," whereas the other wines were scored "like slightly" to "like moderately." The better overall impression of 2017 'Indulgence' wine was likely correlated with greater ratings for aroma and flavor. The overall impression of 2015 'Indulgence' wine was described as citrus, grapefruit, and very pleasant; the overall impression of 2017 'Indulgence' wine was described as bright, very pleasant, and muscat-like. The overall impression of 2015 'Dazzle' wine was described as slightly floral and delicate, and the overall impression of 2017 'Dazzle' wine was described as fruity and stone fruit. 
Table 3. Descriptors for 'Dazzle', 'Indulgence', 'and 'Opportunity' wines at 2 years of storage at $15^{\circ} \mathrm{C}(2015$ wines) and no storage (2017 wines) from an industry sensory panel (26 panelists) done in 2017 on wines produced from grapes grown at the University of Arkansas System Division of Agriculture Fruit Research Station (Clarksville, AR).

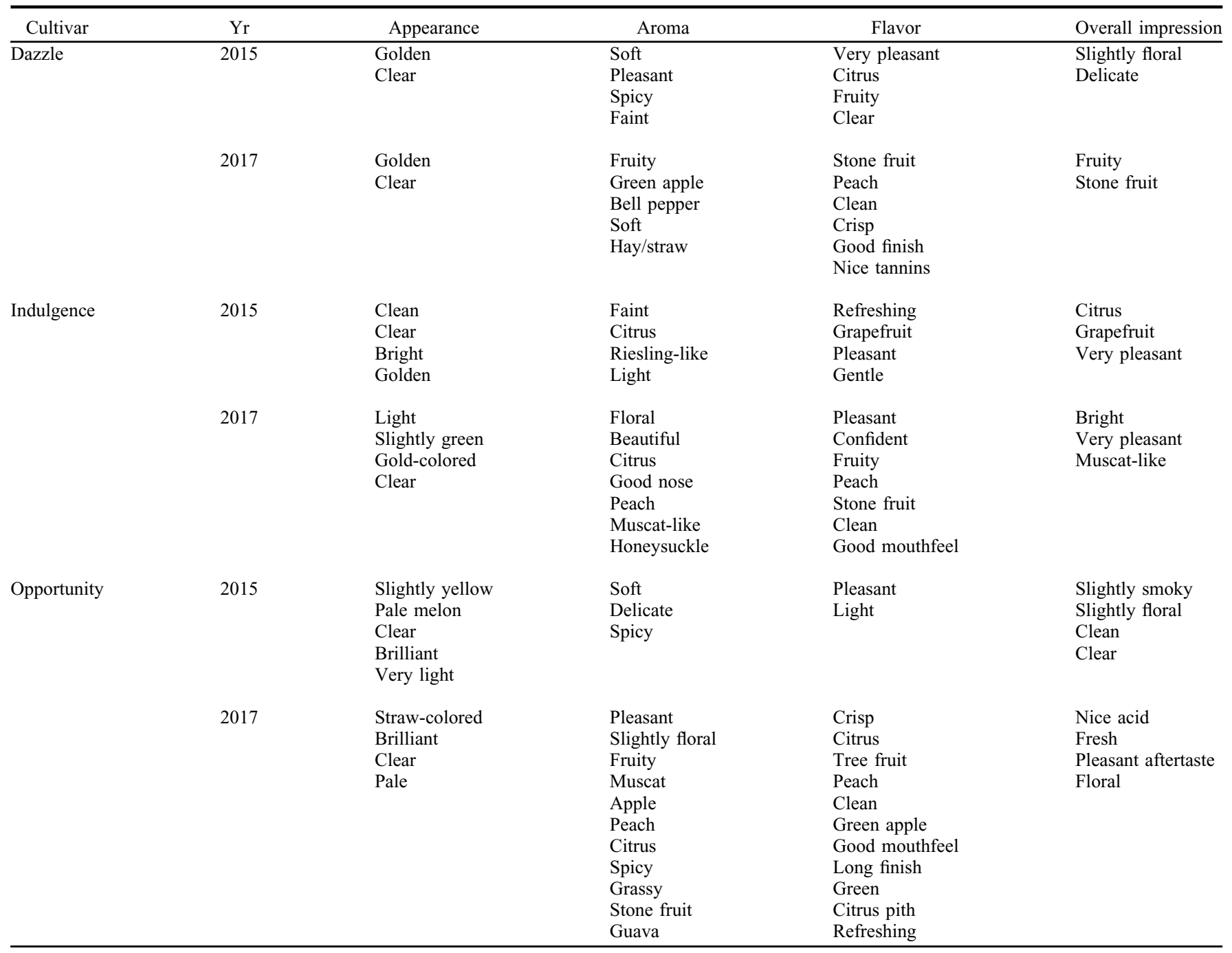

\section{Overall Recommendations}

'Indulgence' and 'Dazzle' provide additional options for white wine grape growers and wineries in Arkansas and the surrounding region. These grapevines are hardy, productive, and show overall good adaptation. The evaluations of the grape, juice, and wine showed that 'Indulgence' had citrus, grapefruit, and muscat-like attributes, whereas 'Dazzle' had floral and stone fruit attributes. These new selections will complement other cultivars in commercial production in Arkansas and other regions with similar growing conditions.
The grapes can be used for production of a single-varietal wine or as a blender to enhance flavor or aroma of other wines. Therefore, 'Indulgence' and 'Dazzle' grapes produced wines with unique and pleasant aroma and flavor characteristics that could provide new opportunities for grape growers and winemakers.

\section{Availability}

The UA System has filed applications for U.S. plant patents on 'Indulgence' and 'Dazzle' grapevines. Nurseries interested in propagating these cultivars must sign a license agreement with the University of Arkansas System Division of Agriculture Technology Commercialization Office (https:// aaes.uada.edu/technology-commercialization/). Contact the Technology Commercialization Office for a list of licensees or to inquire about propagation of 'Indulgence' and 'Dazzle' grapevines.

\section{Literature Cited}

Clark, J.R., J.N. Moore, J.R. Morris, and R. Threlfall. 2018. 'Opportunity' and 'Enchantment' wine grapes for the upper South of the United States. HortScience 53:1208-1211, https:// doi.org/10.21273/HORTSCI13101-18. 